\title{
Terapeutas de 4 Patas - Terapia Assistida por Animais em Unidades de
}

\section{Multideficiência}

\section{Paws Therapists - Animal-Assisted Therapy in Multiple Disability Units}

\author{
Cláudia Gaspar*, Daiana Ferreira**, Sofia Quintas*** \\ *AE Padre João Coelho Cabanita, **Associação Kokua - Cães de Ajuda Social, ***AE Eng ${ }^{\circ}$ Duarte Pacheco
}

\begin{abstract}
Resumo
A intervenção no âmbito das Necessidades Educativas Especiais deve privilegiar atividades que se adequem às características, incapacidades e objetivos de desenvolvimento de cada aluno. Estes pressupostos permitiram a construção e implementação de um projeto de intervenção no domínio da Terapia Assistida por Animais, com cães, em contexto de Unidades de Multideficiência. Definiram-se objetivos individuais e planificaram-se as sessões em função dos mesmos, que decorreram durante dois meses. As atividades e os comportamentos dos alunos foram registados e analisados, tendo sido observado um aumento da motivação e do envolvimento na tarefa, que permitiu uma evolução nos comportamentos-alvo de todos os discentes envolvidos.

Palavras chave: necessidades educativas especiais, multideficiência, terapia assistida por animais.
\end{abstract}

\begin{abstract}
The intervention in the Special Educational Needs scope should privilege activities that fit the characteristics, incapacities and development objectives of each student. These assumptions allowed the construction and implementation of an intervention project in the field of Animal Assisted Therapy, with dogs, in Multiple Disabilities Units context. Individual objectives were defined and the sessions, wich took place for over two months, were planned according to them. The activities and students' behaviors were recorded and analyzed, and there was an increase in motivation and task involvement, which allowed an evolution in the target behaviors of all the students involved.
\end{abstract}

Keywords: Special Educational Needs, Multiple Disabilities, Animal Assisted Therapy.

\section{Enquadramento teórico}

De acordo com Nunes (2008), a multideficiência não é apenas a combinação de deficiências ou o somatório de limitações graves, formando um grupo bastante heterogéneo entre si e afetando todo o processo de desenvolvimento da criança e o modo como ela funciona nos diferentes domínios e contextos de vida. Assim, considerando que a aprendizagem fica gravemente afetada, as respostas educativas têm de ser específicas e especializadas. As crianças com multideficiência formam um grupo heterogéneo, com dificuldades específicas decorrentes da conjugação de limitações funcionais e estruturais e de fatores ambientais adversos que condicionam a sua funcionalidade. Essas limitações dificultam o acesso ao currículo e à participação, diminuindo expressivamente as capacidades de aprendizagem, de aquisição e aplicação de conhecimentos e da resolução de problemas simples (Amaral \& Nunes, 2008).

As UAEAM surgem, portanto, como uma resposta educativa especializada desenvolvida em agrupamentos de escolas que concentram um ou mais grupos de alunos com multideficiência e surdocegueira congénita (art. ${ }^{\circ}$ $26 .^{\circ}$ do DL n. ${ }^{\circ}$ 3/2008). Estas unidades concentram recursos especializados, nomeadamente meios humanos e materiais, com vista à implementação de uma resposta educativa de qualidade. A sua organização deverá considerar, por um lado, as dificuldades manifestadas pelos alunos na esfera do desenvolvimento cognitivo, linguístico, motor e social e, por outro lado, a idade cronológica dos mesmos.

A intervenção assistida por animais em âmbito terapêutico teve início em 1953, com o psiquiatra Boris Lewinson, que, em 1969, percebeu que o cão atuava como um mediador da relação entre a criança e o terapeuta, aumentando a motivação para o desenvolvimento das tarefas (Friesen, 2010). Desde então, a terapia assistida por animais tem sido amplamente usada em pediatria e em ambientes educacionais, com crianças com dificuldades de aprendizagem, multideficiência, autismo e problemáticas de foro emocional e comportamental. De acordo com a organização internacional Animal Assisted Intervention International, entidade de referência na implementação e certificação das Intervenções Assistidas por Animais (IAA), a Terapia Assistida por Animais define-se como uma intervenção orientada por objetivos, de acordo com as necessidades da criança, onde o animal faz parte integral do processo terapêutico. É dirigida por um profissional de saúde e o processo deve ser documentado e avaliado pelo profissional que o dirige. A terapia é desenhada para promover a melhoria no funcionamento físico, social, psicológico, emocional e/ou cognitivo da criança. Pode ser levada a cabo em grupo ou de forma individual, numa ampla variedade de contextos.

Concretamente, o âmbito das Necessidades Educativas Especiais tem sido palco para diversos estudos e 
programas de intervenção assistida por animais (Heimlich, 2011; Prothmann et al., 2006; Limond, Bradshaw \& Cormack, 1997). Em contexto terapêutico, alguns estudos mostram que as crianças experimentam um aumento do estado de alerta e atenção, uma maior abertura e desejo de contacto social quando envolvidas em sessões de terapia com cães (Prothmann et al., 2006). O estudo de Limond, Bradshaw e Cormaçk (1997), que envolveu crianças com síndrome de Down que interagiram com um cão real ou de brincar, mostrou que as respostas não-verbais eram maiores e as respostas verbais das crianças eram mais propensas a ser cooperativas, quando o cão real estava presente.

No que diz respeito aos efeitos da TAA, Heimilch (2011) refere no seu estudo que a medição do ganho cognitivo real em indivíduos com deficiências mentais graves é difícil, ainda que as mudanças imediatas nos comportamentos sejam muitas vezes evidentes. No entanto, estas mudanças positivas não medem com precisão o impacto da terapia no futuro.

Desta forma, este trabalho tem como objetivo a partilha, por um lado, da metodologia usada na implementação da TAA no contexto das Unidades de Multideficiência e, por outro, das evoluções e mudanças registadas nos comportamentos dos alunos.

\section{Fundamentação e Pertinência}

Constituem, entre outros, objetivos das Unidades de Multideficiência: promover a participação ativa, isto é, a inclusão destes discentes nas atividades curriculares; aplicar metodologias e estratégias de intervenção interdisciplinares visando o seu desenvolvimento e a sua integração social e escolar; garantir a criação de ambientes estruturados e significativos; proceder às adequações curriculares pertinentes; adotar opções educativas flexíveis, individualizadas e participadas, implicando uma avaliação constante do processo de ensino/partilha/aprendizagem, assim como o envolvimento parental; garantir os apoios específicos no âmbito das terapias, da psicologia e da orientação e mobilidade; organizar o processo de transição para a vida pós-escolar. Para além dos recursos disponibilizados pela escola para apoio a estes alunos, cabe também às equipas impulsionar a implementação de medidas alternativas promotoras do desenvolvimento, podendo, para isso, estabelecer parcerias com outras entidades. Desta forma, considerou-se que a Terapia Assistida por Animais é uma resposta adequada e benéfica para estes alunos e, neste sentido, foi efetuado o contacto com a Associação Kokua - Cães de Ajuda Social, sediada em Tavira, certificada pela Animal Assisted Intervention International.

\section{Metodologia}

\section{Grupo-alvo}

Treze alunos com multideficiência, com idades compreendidas entre os 6 e os 15 anos, que apresentam acentuadas limitações no domínio cognitivo, associadas a limitações acentuadas no domínio motor e/ou no domínio sensorial (visão ou audição). Estas limitações dificultam a interação natural com o ambiente, colocando em grave risco o desenvolvimento e o acesso à aprendizagem. Apresenta-se uma breve descrição da problemática de cada aluno.

Unidade de Multideficiência do AE Engo Duarte Pacheco. Anderson: aluno de 12 anos com tetraplegia mista, que lhe confere deficiência motora e cognitiva, "geradoras de grande incapacidade". Beneficia de ajudas técnicas com diverso material adaptado (cadeira de rodas e joystick para computador). Tem uma Incapacidade global permanente de 97\%. Dificuldades acentuadas de linguagem. É uma criança com um comportamento adequado no geral, mas com algumas dificuldades na gestão de conflitos.

Marta: aluna de 12 anos com quadro de tetraparésia espástica e grande dificuldade na comunicação/interação com os outros, em consequência de um atropelamento aos 6 anos, do qual resultou um traumatismo craniano encefálico grave c/HTIC (coma prolongado). Usa cadeira de rodas e andarilho. A Marta é uma jovem muito dócil, apresentação, por vezes, alguma obstinação e baixa resistência à frustração. Faz alguma rejeição à escola.

Adélio: aluno de 11 anos com défices acentuados nas funções intelectuais e nas funções neuromusculoesqueléticas, com quadro de hipotonia, estrabismo e de atraso de desenvolvimento psicomotor. Usa cadeira de rodas e andarilho. O Adélio é uma criança com dificuldades na aceitação de regras e baixa resistência à frustração. Procura muitas vezes entrar em conflito com os colegas.

José Maria: aluno de 14 anos com paralisia cerebral com grave atraso mental que determinam um comprometimento grave das funções intelectuais e das funções neuromusculoesqueléticas e relacionadas com o movimento. Utiliza cadeira de rodas de transporte e de posicionamento. Graves dificuldades de linguagem. Tem um comportamento obstinado marcado por dificuldades na aceitação de regras e no seguimento de ordens.

Rafael: aluno de 14 anos com transtorno do desenvolvimento, dentro das Perturbações do Espectro de Autismo, sendo igualmente portador de epilepsia. Faz convulsões diariamente, para o que toma medicação própria. Revela dificuldades de visão e estrabismo. Em 2009 foi submetido a uma cirurgia cerebral, que contribuiu para que melhorasse ao nível da frequência e intensidade das convulsões epiléticas, mas que afetou significativamente as suas capacidades cognitivas, tendo-se verificado uma acentuada regressão. O aluno movimenta-se autonomamente, mas necessita do apoio de um adulto porque cai com frequência. Tem baixa intencionalidade comunicativa e graves dificuldades de interação social.

Inês: aluna de 8 anos portadora da síndrome de microdeleção Koolen de Vries. As características desta síndrome incluem atraso de desenvolvimento intelectual moderado a severo, hipotonia, dificuldades de linguagem e dismorfias faciais características. Tem um comportamento amigável, no entanto é impulsiva e tem baixa resistência à frustração.

Unidade de Multideficiência do AE Padre João Coelho Cabanita. Afonso: aluno de 11 anos com quadro de Tetraparesia Mista com distonia; hipoacusia média no ouvido direito e severa-profunda no ouvido esquerdo. Apresenta um défice cognitivo grave, dificuldades 
acentuadas de linguagem e de atenção/concentração. Tem um comportamento muito impulsivo e, por vezes, agressivo, para com os outros e consigo próprio.

Telma: aluna de 8 anos com um atraso global do desenvolvimento com alterações graves nas funções intelectuais, de linguagem, atenção. Apresenta um comportamento por vezes desafiador e obstinado, com dificuldades na aceitação de regras e na partilha.

Rafaela: aluna de 9 anos com atraso global do desenvolvimento com alterações graves nas funções intelectuais, de atenção e mentais da linguagem. Apresenta um comportamento tímido e introvertido e mutismo seletivo, mas colabora muito positivamente com adultos e crianças.

Daniel: aluno com 8 anos com atraso de desenvolvimento intelectual, dificuldades de aprendizagem e de linguagem, resultantes de encefalopatia crónica - lesão hipóxico-isquémica na região periventricular e centro semioval. Apresenta um comportamento muito dócil e afetuoso, marcado, por vezes, pela imaturidade e alguma oposição perante regras e ordens.

Hugo: aluno de 7 anos com atraso global do desenvolvimento psicomotor com hipotonia acentuada e alterações graves nas funções cognitivas básicas e funções mentais da linguagem. É um aluno emocionalmente muito instável, com comportamentos agressivos e com muitas dificuldades ao nível da atenção/concentração.

Eneas: aluno de 8 anos com diagnóstico de deficiência mental e atraso do desenvolvimento global com alterações graves nas funções intelectuais, psicomotoras e de linguagem. É uma criança muito interativa e bem-disposta, mas muito impulsiva, com dificuldades marcadas na capacidade de atenção/concentração.

Pia: aluna de 11 anos com diagnóstico de tetraparesia espástica com défice motor grave estacionária e alterações graves nas funções intelectuais, da atenção e mentais da linguagem. Apresenta um comportamento afetuoso e com grande intencionalidade comunicativa.

\section{Objetivos}

Objetivo geral: Complementar o plano curricular com as sessões terapêuticas através da introdução estratégica e planeada das cadelas de terapia nas atividades propostas de forma a potenciar o trabalho desenvolvido pela equipa da Unidade, procurando maior impacto nos casos e situações específicas onde as crianças sintam receio, rejeição e/ou dificuldade, aproveitando o cão como forte elemento motivador e multifuncional.

Objetivos Específicos. Os objetivos específicos deste projeto de intervenção foram definidos para cada aluno, com base nas suas problemáticas e competências individuais. A saber:

Anderson: aumentar a capacidade de atenção/concentração e promover a capacidade de resistência à frustração.

Marta: aumentar a capacidade de atenção/concentração, promover a capacidade de resistência à frustração e desenvolver a motricidade fina.
Adélio: aumentar a capacidade de atenção/concentração, promover a capacidade de aceitação de regras e desenvolver a motricidade fina.

José Maria: aumentar a capacidade de atenção/concentração, promover a capacidade de aceitação de regras, promover a comunicação intencional.

Rafael: desenvolver estratégias de comunicação não verbal, aumentar a capacidade de atenção/concentração.

Inês: aumentar a capacidade de atenção/concentração, promover a capacidade de resistência à frustração e controlar comportamentos de impulsividade.

Afonso: aumentar a capacidade de atenção/concentração e promover a afetuosidade e diminuir os comportamentos agressivos.

Telma: aumentar a capacidade de atenção/concentração, promover a afetuosidade e diminuir os comportamentos agressivos e controlar comportamentos de impulsividade.

Rafaela: promover a comunicação intencional e aumentar a capacidade de atenção/concentração.

Daniel: controlar a impulsividade e promover a capacidade de resistência à frustração.

Hugo: aumentar a capacidade de atenção/concentração e promover a capacidade de resistência à frustração.

Eneas: controlar comportamentos de impulsividade e aumentar a capacidade de atenção/concentração.

Pia: desenvolver estratégias de comunicação não-verbal, promover o desenvolvimento motor global e desenvolver a capacidade de seguir ordens simples

\section{Procedimentos}

Após um primeiro contacto entre as equipas das duas Unidades e a terapeuta responsável pela Associação Kokua, foi agendada uma sessão experimental com todos os alunos. Esta sessão realizou-se no 2. ${ }^{\circ}$ período letivo, teve a duração de 30 minutos e a recetividade dos alunos, a motivação e o envolvimento demonstrados levaram as equipas a acreditar que a TAA seria uma mais-valia para a promoção do desenvolvimento dos alunos e a elaborar um projeto de intervenção para apresentação às Direções dos dois Agrupamentos.

Nesta primeira fase de elaboração, procedeu-se à discussão e análise de cada caso, estabeleceram-se os objetivos, definiu-se um cronograma de sessões para todo o $3 .^{\circ}$ período e foram solicitados os consentimentos informados aos encarregados de educação dos alunos e resposta a um questionário sobre comportamentos e possíveis alergias. Este passo inicial terminou com a aprovação do projeto pelas Direções, tendo sido o financiamento concedido pela Câmara Municipal de Loulé.

Numa segunda fase, a de implementação, procedeu-se ao desenvolvimento dos planos de ação individuais e das atividades em função dos objetivos específicos definidos para um período de dois meses. Com o decorrer das sessões, houve a necessidade de se fazer uma adaptação das tarefas, atividades, materiais ou dinâmicas de forma a melhor alcançar os objetivos propostos. Foi feito um registo de toda a informação sobre a evolução de cada caso individual, através de grelhas de avaliação informais, construídas para cada objetivo. Estas grelhas 
permitiram avaliar a intensidade de comportamentos-chave que os alunos tinham em sessão e que iam ao encontro dos objetivos definidos.

A última fase do projeto consistiu na análise dos resultados, sistematização da informação e partilha com as respetivas Direções dos dados recolhidos, através de relatório, e reflexão crítica sobre o impacto da intervenção nos casos individuais e no funcionamento da Unidade em geral.

\section{Metodologia da intervenção em sessão}

As sessões de terapia decorreram com uma periodicidade semanal com a duração de 30 minutos. Cada sessão foi desenhada e planificada em função dos objetivos individuais, como já foi referido, e levando em consideração as características de cada aluno, não só ao nível das suas competências e necessidades mas também da sua personalidade e comportamento típico. As sessões organizaram-se em três atividades - introdutória, principal e final - e foram utilizados vários materiais lúdico-pedagógicos. As atividades foram desenvolvidas usando duas cadelas diferentes, uma mais calma (Sueca) e outra mais ativa (Luna), as duas de raça Labrador Retriever. A Sueca interveio com os alunos que respondem melhor a atividades que exigem menos movimentação no espaço e maior foco de atenção. Por sua vez, a Luna esteve presente nas sessões com os alunos que beneficiam de atividades mais dinâmicas e com maior nível de movimento. Independentemente das características de cada cadela, o cão de terapia pode assumir nestas sessões vários papeis: motivador, reforçador, regulador das emoções, estímulo multissensorial e de apoio.

\section{Avaliação e discussão de resultados}

Como foi referido anteriormente, foram construídas grelhas informais de avaliação do desempenho dos alunos em função dos objetivos estabelecidos para cada um, usando uma escala de classificação de 4 ou 5 pontos, em que a pontuação máxima se adequa ao desempenho máximo individual. A observação e o registo dos comportamentos foram efetuados por voluntários que acompanhavam a terapeuta durante as sessões.

Tabela 1.

Escalas de classificação para cinco objetivos individuais

\begin{tabular}{lcc}
\hline Objetivos & Comportamentos & $\begin{array}{c}\text { Classific } \\
\text { ação }\end{array}$ \\
\hline Aumentar a & Até 5 min. & 1 \\
capacidade de & Até 10 min. & 2 \\
atenção/ & Até 15 min. & 3 \\
concentração & Até 20 min. & 4 \\
& Até 30 min. & 5 \\
Controlar a & Comportamento impulsivo & 1 \\
impulsividade & Ignora pedidos de controlo & 2 \\
& Controlo solicitado, mas repete & 3 \\
& Controlo solicitado & 4 \\
& Auto-controlo & 5 \\
Desenvolver & Inexistência & 1 \\
estratégias de & Contacto visual & 2
\end{tabular}

\begin{tabular}{|c|c|c|}
\hline comunicação & Expressões faciais & 3 \\
\hline não verbal & Interação física (toca, agarra) & 4 \\
\hline & Vocalizações comunicativas & 5 \\
\hline Promover a & Só comportamento agressivo & 1 \\
\hline afetuosidade e & Predomina o comportamento & 2 \\
\hline diminuir os & agressivo & \\
\hline comportament & Igual proporção & 3 \\
\hline os agressivos & $\begin{array}{l}\text { Predomina comportamento } \\
\text { afetuoso }\end{array}$ & 4 \\
\hline & Só comportamento afetuoso & 5 \\
\hline Aumentar a & Evita a comunicação & 1 \\
\hline comunicação & Não responde & 2 \\
\hline verbal & Responde não verbalmente & 3 \\
\hline intencional & Responde verbalmente & 4 \\
\hline & Comunica intensionalmente & 5 \\
\hline
\end{tabular}

Para além dos objetivos individuais, foram ainda avaliados a motivação e o envolvimento na tarefa de todos os alunos. Desta forma, procedeu-se a uma avaliação qualitativa do desempenho e evolução dos alunos. Apresenta-se a síntese da evolução registada, ao longo das sessões.

O Anderson, durante todas as sessões, sempre demonstrou uma forte motivação pela realização da tarefa - inclusive nas mais exigentes, verbal ou fisicamente. Perante momentos de frustração, aceitou muito bem as orientações de autorregulação - as quais eram repetidas nas seguintes sessões.

A evolução da Marta foi pouco marcada pois sempre teve um envolvimento quase perfeito. Os principais resultados da evolução da Marta não foram registados em sessão, mas sim fora dela: a Marta alterou de faltar $100 \%$ a estar presente $100 \%$ das tardes de terça-feira, com impacto forte no seu interesse pela escola.

O Adélio iniciou a terapia com comportamentos de afrontamento com os colegas, profissionais e, inclusive, cadelas de terapia, que desapareceram por completo quando uma das cadelas se engasgou e ficou com comprometimento respiratório. Esse momento foi chave na mudança de atitudes, passando de ser uma criança crítica e pouco cuidadoso para um indivíduo preocupado e atencioso.

O envolvimento do José Maria em sessão era muito dependente da atividade proposta: atividades para as quais se sentia motivado eram realizadas com muita facilidade e foco; atividades com menor nível de motivação, ou com aumento do nível de dificuldade, resultavam-lhe difíceis e eram realizadas com baixo nível de concentração.

Depois de se descobrir que tocar nas cadelas de terapia com os pés era muito agradável para o Rafael, o seu contacto visual e a interação com o terapeuta, estabelecimento de contacto físico (ex.: pegar na mão do terapeuta para levar à cadela) e atenção-concentração na tarefa foram de uma evolução notavelmente positiva. Nas últimas sessões houve comportamentos muito positivos: entrada autónoma e voluntária na sala de sessão; contacto autónomo e voluntário com as mãos nas cadelas; vocalizações e movimentos físicos típicos nele de demonstração de agrado.

Com um início marcado por comportamentos impulsivos e dificuldade de organizar e responder às 
frustrações, a evolução da Inês foi clara de sessão para sessão. Trabalhando maioritariamente em grupo, o seu carinho e vontade de ajudar foi determinante no desenvolvimento de estratégias muito úteis frente às dificuldades (ex.: se um colega se chateava, ela respirava fundo e organizava uma frase para, de forma subtil, se demonstrar disponível para prestar apoio).

Inicialmente, o Afonso rejeitava a aproximação e interação com o animal, tendo isto alterado drasticamente com o passar das sessões. Nas sessões finais, havia sempre procura visual próxima e contacto físico (ex.: festas, beijos, dar de comer). Quando descrito pelos profissionais da Unidade que o Afonso estaria a ter um dia mais complicado, isto não se via refletido na sessão - o que nos faz pensar que o cão de terapia poderá atuar como uma atenuante dos comportamentos inapropriados.

Em todas as sessões, a Telma demonstrou uma dificuldade grande de manter a atenção e concentração na tarefa. No seu comportamento, relativamente ao animal, notaram-se melhorias muito positivas: no início a Telma rejeitava o animal com choro e gritos, passando a ter uma atitude autoritária, tendo, por fim, alterado o registo de interação para palavras suaves, gestos carinhosos como festas e beijos e uma curiosidade sempre presente.

A Rafaela, apesar da sua forte inibição, sempre teve uma forte comunicação com o terapeuta e o cão de terapia. Muito envolvida nas tarefas e com um nível de compreensão muito razoável, por vezes a maior dificuldade prendia-se com a manutenção da atenção na tarefa, deixando alguns pontos por concluir e precisando de apoio neste aspeto; estas dificuldades eram facilmente superadas com a proposta de realizar atividade de movimento, isto é, passear a cadela com a trela e realizar pedidos como senta e deita.

O Daniel, desde cedo, beneficiou muito da interação com o animal como elemento de apoio na sua regulação e controlo de impulsividade. Frequentemente, quando chamado à atenção, realizava um ajuste do seu comportamento e estabelecia imediatamente contacto físico com a cadela de terapia. De trato doce e cuidadoso, as atividades propostas sempre foram realizadas com atenção e motivação.

Inicialmente o Hugo foi complicado: com muitas fugas e comportamentos agressivos para demostrar desagrado. Com o avançar das sessões, procurando propor diferentes atividades, acabou por se utilizar o cão de terapia como reforço secundário, isto é, foi utilizada a bola de pilates para proporcionar movimento, o qual era interrompido para desempenhar a tarefa proposta com o animal. Isto permitiu um aumento da sua tolerância à frustração, respeito pelos tempos de espera, uma melhoria do contacto visual e envolvimento na tarefa.

O Eneas apresentava no início um comportamento impulsivo e de baixa capacidade de foco na tarefa proposta. Rapidamente este comportamento se foi alterando; o seu comportamento em sessão começou a ser de forte interesse e concentração para melhor entendimento das atividades propostas.

A Pia, nas primeiras sessões, requereu muito apoio à hora de estabelecer contacto físico com a cadela, questão que evoluiu marcadamente - no final, a Pia era capaz de acariciar a Sueca após solicitação. O seu envolvimento na sessão sempre foi grande e a sua capacidade de demonstrar agrado ou desagrado foi desenvolvida com muito sucesso, utilizando as suas expressões faciais. Também se observou evolução clara no que se refere à sua motricidade global. Conseguiu seguir ordens simples como o aperta, segura, empurra, abre a mão e solta, onde se respeitaram sempre os seus tempos de resposta.

Em jeito de análise final, consideramos que este projeto trouxe mais-valias muito interessantes para os alunos das duas Unidades. A presença das cadelas de terapia revelou-se um facilitador inegável para o envolvimento dos alunos nas tarefas propostas, o que permitiu trabalhar algumas competências de um modo mais aliciante para as crianças. Ainda que a medição de ganhos cognitivos não seja possível de fazer após uma intervenção tão breve, consideramos que foram verificadas mudanças de comportamento significativas durante as sessões, como um aumento claro dos níveis de atenção/concentração, um maior autocontrolo dos comportamentos impulsivos, o desenvolvimento de formas de comunicação não verbal por parte dos alunos que não falam, um aumento da intencionalidade comunicativa dos alunos com maiores dificuldades ao nível da expressão verbal e uma diminuição de comportamentos de agressividade.

\section{Referências}

Amaral, I. \& Nunes, C. (2008), Educação, Multideficiência e Ensino Regular: um Processo de Mudança de Atitude. Diversidades, 20, 4-9.

Animal Assisted Intervention International. (s.d.). Animal Assisted Intervention. Disponível em: http://www.aai-int.org/aai/animal-assisted-intervention/

Decreto-Lei n³/2008, de 7 de janeiro. Diário da República, 4/2008 - I Série. Ministério da Educação. Lisboa.

Friensen, L. (2010). Exploring Animal-Assisted Programs with Children in School and Therapeutic Contexts. Early Childhood Educ J, 37, 261-267.

Heimlich, K. (2001). Animal-Assisted Therapy and the Severely Disabled Child: A Quantitative Study. Journal of Rehabilitation, 64 (4), 44-54.

Limond, J., Bradshaw, J., \& Cormack, K. F. (1997). Behavior of children with learning disabilities interacting with a therapy dog. Anthrozoos, 10(2/3), 84-89.

Nunes, C. (2008). Alunos com multideficiência e com surdocegueira congénita. Organização da resposta educativa. Lisboa: Direcção-Geral de Inovação e de Desenvolvimento Curricular. Direção de Serviços da Educação Especial e do Apoio Sócio - Educativo.

Prothmann, A., Bienert, M., \& Ettrich, C. (2006). Dogs in child psychotherapy: Effects on state of mind. Anthrozoos, 19(3), 265-277.

\section{Agradecimentos}

Um agradecimento especial às Direções dos Agrupamentos de Escolas Eng ${ }^{\circ}$ Duarte Pacheco e Padre João Coelho Cabanita, pela abertura e disponibilidade para a implementação deste projeto, e à Câmara Municipal de Loulé, pelo apoio financeiro. 